\title{
The Impact of Flipped Learning on Procrastination and Students' Attitudes toward It
}

\author{
Atef Abuhmaid ${ }^{1, *}$, Mohammad Abood ${ }^{2}$ \\ ${ }^{1}$ Department of Curricula and Instruction, Hashemite University, Jordan \\ ${ }^{2}$ Department of Psychology and Counselling, Hashemite University, Jordan
}

Received December 6, 2019; Revised January 2, 2020; Accepted January 13, 2020

Copyright $\bigcirc 2020$ by authors, all rights reserved. Authors agree that this article remains permanently open access under the terms of the Creative Commons Attribution License 4.0 International License

\begin{abstract}
The current study aimed at investigating the impact of flipped learning model on university students' procrastination and their attitudes toward flipped learning. The study utilized a quasi-experimental research design, which employed Tuckman's procrastination test, which was administered to all 80 students enrolled in two sections at "computer in education" course offered by the Faculty of education at Hashemite University, Jordan during the first semester of the academic year 2018/2019. The study utilized two research instruments: Tuckman's "Procrastination Test" which consisted of 16 items with five alternatives for each item according to Likert Scale and attitudes questionnaire. Students were divided randomly into two groups: control and experimental groups. The 40 students in the experimental group were taught by flipped learning model while the 40 students in the control group were taught by a traditional model. To answer the research questions, means and standard deviations were calculated for students' responses on the Tuckman's procrastination test. The results of the study showed that procrastination persisted as there were no significant differences at the level of $(\alpha=0.05)$ for the benefit of flipped learning model despite the positive attitudes students showed toward flipped learning on the attitudes questionnaire. Based on the results obtained, procrastination proved to be a tough issue, which may require further attention and psychological intervention to help students to overcome the issue, capitalizing on the positive attitudes they showed toward flipped learning.
\end{abstract}

Keywords Teaching Methods, Higher Education, Procrastination

\section{Introduction}

There are expectations and demands on educational institutions to provide a nurturing and rich learning environment in order to foster students' learning and development. Universities are required to provide resources, infrastructure, and teaching that enable students to make the most of their academic lives. In this regard, and in light of the growing competitiveness, universities worldwide compete to provide competitive and attractive learning environments ad opportunities for their prospective students. On the other hand, students are expected to benefit from what their universities provide so they acquire and develop their knowledge, skills, and personalities. Students are required to focus on their academic duties and achievement. However, students face various and competing responsibilities that often tamper their success and academic expectations [1]. In particular, as students try to manage long and medium-term academic goals they also have to deal with social, psychological and personal demands while they have to stay focused on their goals. Often, they fall into the trap of procrastination; which is a challenging and serious issue for academic performance $[2,3]$.

\subsection{Procrastination}

Procrastination is a common problem characterized by the tendency to giving in to feeling good [4]. Lay and Silverman [5] defined procrastination as putting off acting on intentions. People tend to avoid tasks which they find unpleasant and prefer to engage in activities which are more rewarding in the short term over the long term [6]. Thus, procrastination is a voluntarily and irrational delay of an intended course of action even though the outcomes are expected to be worse as a result of the delay [7]. In addition, the postponement of tasks causes mental stress which is the result of opening new unresolved tasks [8].

Apparently, procrastination can interfere with academic performance. Studies worldwide have reported procrastination among university students [9-11]. 
According to You [12], 70\% of college students consider themselves as procrastinators. Earlier, Steel [13] reported that $80-95 \%$ of university students admitted procrastination and $50 \%$ of them procrastinate consistently and problematically. In Jordan, a study conducted on university students by Ghazal [14] showed that $81.9 \%$ of students exhibited high or average levels of procrastination.

A negative correlation between procrastination and students' academic performance has been reported [12, 15-19]. Often, procrastination leads to cramming strategies, as students postpone study-related activities to the last possible time before deadlines, which may point to a lack of time management skill [20-22]. The postponement of academic tasks and duties do not resolve them and they become daunting as deadlines approach making optimal performance highly unlikely [16]. In addition, procrastination might represent difficulties in setting goals independently [2] and self-managing skills [23]. Furthermore, [19] stressed the impact of procrastination on academic dishonesty among students in the form of increased cheating.

Students tend to procrastinate when they are not motivated and feel disengaged from the learning experience. Academic procrastination, according to [24], is a motivational problem, and it is associated with lack of self-determined motivation [25]. Thus, addressing students' motivation can impact their tendency to procrastinate. The three motivational needs, e.g. competence, relatedness, and autonomy, are believed to have direct impact on students' motivation [26]. When students feel incompetent, they might tend to procrastinate because they fear academic failure [27]. In addition, students might procrastinate because they do not have a sense of relatedness or belongingness and feel isolated from the learning environment. The autonomy, according to [26], is translated into freedom to choose which activities to engage in and to choose how to deal with them. Autonomy can empower students and give them control over their learning and become more responsible and engaged. Satisfying the three motivational needs can lead students to perceive that their psychological needs are satisfied [28] and they become more engaged in learning activities.

The relation between procrastination and the use of digital media has been highlighted. As students increasingly spend excessive time online unaware of the passage of time while they procrastinate and postpone academic tasks [29]. Therefore, according to [30], the penetration of digital technologies, in spite of their benefits, has its digital downside. Students' distraction by electronic devices in classrooms has been reported in many forms; such as playing games, social networking, and cheating by accessing information online in order to answer exam questions [31, 32]. In addition, faculty members are increasingly faced with students' negative behaviors driven by technology use such as addiction, procrastination [33], students' shorter attention span and cheating from online resources instead of learning and solving problems [34]. Nevertheless, faculty members are still required to help students learn and they should adapt to these changes in the digital generation by adopting suitable teaching strategies that address such changes and attract students' attention.

Innovative teaching strategies should consider the fact that today's students are distinctly digital [35, 36]. Students' relentless use of digital media often comes at the cost of their attention and focus on accomplishing academic tasks and pursuing goals [33, 37, 38]. In addition, their perseverance to pursue academic long-term goals decreases by time considering the overwhelming exams and tasks so; they might start to lower their ambition. Accordingly, faculty members should develop their teaching methods and strategies in order to address the emerging issues facing education including procrastination.

\subsection{Flipped Learning}

Teaching strategies are strong influencers of students' learning. Appropriate teaching practices are linked to students' motivation to learn [39, 40] and may help students in dealing effectively with procrastination. Thus, teaching strategies that utilize digital media can make more sense to this generation. Flipped learning model is one of the new promising models which speaks the "the language" of students in the digital age. The model keeps track of students' learning before, during and after class time while utilizing the power of digital media [41]. It primarily utilizes short instructional videos as a medium for delivering contents in the form of condensed chunks of the curriculum, which may help students stay aligned to tasks and development during the course. Chunking the curriculum has been mentioned as an effective strategy for helping students to learn better [42, 43]. Therefore, chunking the curriculum into short instructional videos may help students to deal effectively with procrastination and to stay on track. In addition, positive effect of flipped learning has been reported on students' motivation to learn $[44,45]$, academic achievement [46], and attitudes [45, 47].

Flipped learning model has gained increasing attention since the inception of the term around 2011 [48]. The model is an innovative approach to teaching and learning in light of ubiquitous and advancement digital tools [49-52]. The model relies on the power of new technologies in order to provide students with the content and materials in digital formats making them accessible to students outside the classroom paving the way to class time to be more engaging and active [52]. The basis for flipped learning model is that students come to the classroom ready for the learning experiences [53].

Flipped Learning redesigns learning and uses both group and individual learning spaces more productively, so, 
direct instruction moves from the group learning space to the individual learning space. Technology can play valuable role in transmitting information [54] which can be done outside the classroom enabling students to move on their own pace relying on the flexibility of technology. Accordingly, group space becomes a dynamic, interactive and the teacher guides students as they apply concepts and engage creatively with the learning experience [55]. Recently, there has been much emphasis on the notion that flipped learning is not a teaching strategy, rather; it is a meta-strategy, which lays the ground for creative teaching strategies to be implemented during the face-to-face time; such as, cooperative learning, inquiry-based instruction, and project-based learning. This becomes possible because lecturing shifts from the class time to the home time. In addition, the way in which instructional short videos are designed, organized and delivered to students within flipped learning may help them both access the curriculum in a favorable way for them, and stay on track in their learning.

In-class time activities are specifically designed to enable students to use the knowledge they gained before the class. Thus, students are required to deal with a more realistic situation than merely listening and understanding knowledge presented in the traditional classroom. Accordingly, students have a better chance to link their knowledge to prior knowledge in order to effectively deal with tasks and activities designed in the learning experience [53]. In-class time is freed from lecturing and information transmission in flipped classroom in order to achieve higher order and deeper levels of learning [56]. That is, students become engaged in higher order thinking activities such as problem-solving, analyzing, discussion, and debates [57] under the guidance of the teacher [48]. In addition, as student's complete homework in classroom [58] teachers can have better insight into students' learning. Therefore, instead of lecturing and being the sole provider of knowledge, according to Butt [59], students may use the classroom time to apply the concepts and knowledge making them more engaged and responsible. The teacher guides students' learning in the classroom instead of transferring lecture notes to the notebooks of the students without passing through their brains [51] giving learning more meaning to students.

Online video is becoming a favorable medium for conveying messages and searching for contents. Students watch videos as a daily routine on various social media platforms for different purposes including academic. The explosive growth of online video which is fueled by the rise of websites such as YouTube and the expansion of broadband ownership among the public [60]. Users share video clips on social media such as Facebook, Instagram, Twitter, YouTube, and WhatsApp. Thus, weaving learning videos into their digital fabric sounds natural and might be rewarding for their learning. Zhang, Zhou [61] emphasis the importance of integrating instructional video into e-learning systems. Watching short videos (3-8 minutes) can help students to break the course into pieces easier to grasp. Although flipped learning is not confined to using videos as the only medium for content delivery, videos remain favorite.

Flipped learning can motivate students to learn [48]. The essence flipped learning is to shift the power in learning from teachers to the students by redesigning learning experiences that give them more control over their learning. Students can choose when and how to watch assigned instructional videos before classes. In addition, the in-class learning activities segment of flipped learning, are mainly practical and require students to play active role and become engaged [56]. Active learning during the can also provide more opportunities to strengthen bonds between students, giving them a sense of relatedness to the course and to other students. Furthermore, flipped learning shifts the application of new knowledge students acquire from home to the classroom where the teacher can play a major role in helping them solve problems and make sense of what they had learnt [62]. Otherwise, students might become frustrated and procrastinate because they feel incompetent to solve course-related problems, resulting in disengagement.

An increasing number of research studies have examined the effectiveness of flipped learning [62, 63]. Flipped learning model can enhance teacher-student interactions, facilitate deep learning, and foster millennials' engagement $[42,64]$. In addition, it was found that flipped learning can improve students' motivation [44, 48]. Nevertheless, AlJarrah, Thomas [65] examined the learning behaviors and characteristics of students in a course adopted flipped learning relying on learning analytics data from a learning management system. The study showed that procrastination persisted among students as the day of the lecture time had the maximum number of accesses to learning materials and the peak access occurred during the lecture time.

\subsection{Purpose and Significance of Research}

The current study aimed at examining the impact of flipped learning model on students' procrastination as well as students' attitudes of students toward flipped learning. More specifically, the study will try to answer the following two research questions:

- Are there significant differences at the level $(\alpha=0.5)$ between students' procrastination due to the teaching style (Flipped/traditional)?

- What are the attitudes of university students' toward flipped learning?

\section{Materials and Methods}

In this section, the research design, participants, and data collection instruments will be described. 


\subsection{Research Method}

The current study utilized a quasi-experimental methodology research design with a pretest-posttest. Two groups were selected: one experimental group and one control group.

\subsection{Research Population and Sample}

Eighty students enrolled in the "computers in education" course participated in the study during the first semester of the academic year 2018/2019. All students were asked to complete Tuckman's Procrastination Test. Students were divided randomly into two groups: control and experimental groups. Forty students in the experimental group were taught by flipped learning model while the 40 students in the control group were taught in a traditional model. The equivalence of the two groups was calculated through independent samples $\mathrm{t}$-Test, which showed no significant differences between the two groups. All the enrolled students in the course were females so the gender issue was not a variable in the study considering that the class teacher program targets females. In addition, 40 students $(50 \%)$ were in their 2nd year, $32(40 \%)$ were in the 3 rd year, and eight (10\%) in other years.

\subsection{Data Collection Tool}

In order to gather data from participants, two data collection tools were used: Tuckman's Procrastination Test and the students' attitude questionnaire. The Tuckman's Procrastination Test provides a measure of "the tendency to waste time, delay, and intentionally put off something that should be done" [66, p. 479]. The test consisted of 16 items and each item had four alternatives; $1=$ "that's not me for sure" $2=$ "That's not my tendency," $3=$ "That's my tendency," and $4=$ "that's me for sure." Four negative items (7, 12, 14, and 16) were reversed during the analysis. Tuckman's validation study, showed adequate reliability and validity, with a significant correlation ( $\mathrm{r}=.54)$. Recent studies have used Tuckman's Procrastination Test, with results showing high reliability, and validity. Evidence shown in the form of high positive correlations with other procrastination measures, and significant inverse relationships with behavioral measures of timely task completion. The second research tool was the attitudes questionnaire, which was developed based on the literature and previous studies and consisted of 10 items. Responses to the scale were measured on a five-point Likert scale ranged as follows: $5=$ strongly agree, $4=$ agree, $3=$ neither disagree nor agree, $2=$ disagree, and $1=$ strongly disagree. The validity of the instrument was assessed by a panel of 12 faculty members. Additionally, Cronbach's alpha was used to assess the reliability of the instrument, which was found 0.87 reflecting exemplary reliability of the instrument.

\subsection{Procedure}

Eighty students enrolled in the "computers in education" participated in the current study. They were divided randomly into two groups: control and experimental groups. The 40 students in the experimental group were taught by flipped learning model while the 40 students in the control group were taught in a traditional model. All 80 students in the two groups completed Tuckman's Procrastination Test at the beginning of the semester.

Instructional videos were created for students to use in the course. Students were instructed at the beginning of the semester to engage actively with the videos as they were aligned strictly to the course contents and an introductory video explained to them what they are expected to do when watching the instructional videos, including paying attention and writing questions and comments.

At the end of the treatment, which lasted for the whole semester, students in both groups completed Tuckman's Procrastination Test and students in the experimental group filled the attitudes questionnaire.

\section{Findings}

The current study aimed at examining the impact of flipped learning model on students' procrastination as well as students' attitudes of students toward flipped learning at Hashemite University of Jordan. There is no statistically significant effect at $(\alpha=0.05)$ of teaching by Flipped learning model on students' academic procrastination.

To answer the first research questions, which stated "Are there significant differences at the level $(\alpha=0.5)$ between students' procrastination due to the teaching style (Flipped/traditional)?" means and standard deviations were calculated for students' responses on the Tuckman's procrastination test. Table (1) shows the differences for both the experimental and control groups on the pre and post-tests.

Table 1. Means and Standard Deviations of student's answers in the two groups on the pre/post-tests on Tuckman's procrastination test

\begin{tabular}{|c|c|c|c|c|c|}
\hline \multirow{2}{*}{ group } & \multirow{2}{*}{$\mathrm{N}$} & \multicolumn{2}{|c|}{ Pre-Test } & \multicolumn{2}{|c|}{ post-Test } \\
\cline { 3 - 6 } & & $\mathrm{M}$ & $\mathrm{SD}$ & $\mathrm{M}$ & $\mathrm{SD}$ \\
\hline Control & 40 & 3.12 & 0.272 & 3.03 & 0.471 \\
\hline Experimental & 40 & 3.15 & 0.280 & 3.16 & 0.518 \\
\hline
\end{tabular}


Table 2. The results of ANCOVA of students' academic procrastination on the post test

\begin{tabular}{|c|c|c|c|c|c|}
\hline Source & $\begin{array}{c}\text { Sum of } \\
\text { Camanc }\end{array}$ & DF & $\begin{array}{c}\text { Mean } \\
\text { camara }\end{array}$ & F & Sig. \\
\hline Post-test & 0.17 & 1 & 0.17 & 0.689 & 0.412 \\
\hline Teaching strategy & 0.156 & 1 & 0.156 & 0.633 & 0.431 \\
\hline Error & 9.136 & 37 & 0.247 & & \\
\hline Corrected total & 9.484 & 39 & & & \\
\hline
\end{tabular}

Table 3. Means and Standard Deviations of students' responses on the attitudes toward flipped learning questionnaire

\begin{tabular}{|c|c|c|c|c|}
\hline No & Item & Rank & Mean & SD \\
\hline 1 & Flipped learning supports self-learning & 1 & 4.6 & 0.71 \\
\hline 2 & Flipped learning provides opportunities for active learning (in classrooms) & 2 & 4.3 & 0.95 \\
\hline 3 & Flipped learning does not add to my screen time & 3 & 4 & 0.72 \\
\hline 4 & Flipped learning makes lectures available any time & 4 & 3.9 & 0.63 \\
\hline 5 & Flipped learning reduces frustration by providing support to students & 5 & 3.8 & 0.81 \\
\hline 6 & Flipped learning enables students to communicate & 5 & 3.8 & 0.75 \\
\hline 7 & I think teachers are more available in flipped learning & 6 & 3.7 & 0.61 \\
\hline 8 & I think videos are great in teaching and learning & 6 & 3.7 & 0.78 \\
\hline 9 & I prefer enrolling in flipped learning courses in the future & 7 & 3 & 0.82 \\
\hline \multirow[t]{2}{*}{10} & Flipped classroom has not improved my learning & 8 & 2.7 & 0.93 \\
\hline & Overall & & 3.73 & 0.77 \\
\hline
\end{tabular}

Table (1) shows an observed difference between the two means of the groups on the post-test due to the teaching style (Flipped and traditional). To examine the significance of the observed difference, ANCOVA was used for students' answers in the post-test due to the teaching style after excluding the pre-test students' answers. The results are presented in Table (2).

Table (2) shows that there are no significant differences at the level $(\alpha=0.05)$ on Tuckman's procrastination test and the value of "F" was (0.633). The results show that Flipped learning model did not impact students' academic procrastination level.

The second research question stated "What are the attitudes of university students' toward flipped learning?" to answer this question and to investigate students attitudes toward their flipped learning experience, means, standard deviations, and ranks were calculated for the attitudes questionnaire as shown in Table (3).

Table (3) shows that the highest mean ( $M=4.6$, $\mathrm{SD}=0.71$ ) was for the item stated "Flipped learning supports self-learning" and the second highest was for the statement "Flipped learning provides opportunities for active learning (in classrooms)" (M=4.3, $\mathrm{SD}=0.95)$. Noticeably, the item "Flipped learning does not add to my screen time" scored high $(\mathrm{M}=3.8, \mathrm{SD}=0.63)$. The item "Flipped classroom has not improved my learning" scored the least $(\mathrm{M}=2.7, \mathrm{SD}=0.93)$. Overall, students had positive attitudes toward flipped learning experience with a high overall mean $(\mathrm{M}=3.73, \mathrm{SD}=0.77)$.

\section{Discussion}

The current study investigated the impact of flipped learning model on students' academic procrastination and students' attitude toward it. The findings showed no significant impact of flipped learning on students' academic procrastination despite the positive attitude they showed toward flipped learning as a teaching and learning model. These findings contradicted the researchers' initial expectations. Although students were required to watch short videos before classes, their procrastination level was not affected due to the teaching strategy. The results confirm findings from earlier study by [65] which showed that procrastination persisted among all three categories of students involved in their study, and that they may delay watching videos to just before, or even at the beginning of, the class. Therefore, students may continue to procrastinate in an "innovative" way in order to fulfill the course requirements while procrastinating.

The finding may point to the complexity of dealing with the deep rooted problem of procrastination [66, 67]. Thus, the finding may suggest that although the teaching model has a crucial rule in students' learning [39, 40], additional efforts might be needed to helping students to tackle their procrastination. This confirms that procrastination is a deep-rooted dispositional trait with cognitive, behavioral and emotional components $[6,68]$. Therefore, procrastination must be treated by targeting related factors and causes mentioned in previous studies such as the failure to delay gratification, self-regulation, 
time management, and personal traits [21, 69].

Fortunately, despite the findings of the current study, the time saved by flipped learning model can be invested to reach all students and customize individualized plans and programs that can include counselling directed specifically to helping them overcome procrastination. Additionally, the positive attitudes of students toward their flipped learning experience confirms previous findings which show students' satisfaction [45, 70]. However, despite students' satisfaction and high scores of their flipped learning experience, they remained unsure of the impact of flipped learning on learning which might reflect their uncertainty associated with the novel idea of flipped. Therefore, flipped learning might need more time for students to absorb they idea properly and readjust their practices for the benefit of their learning.

\section{Conclusions}

In conclusion, implementing flipped learning model and benefiting from new technologies can free classroom time and improve students' interest in learning. Nevertheless, procrastination might be a challenging and an entrenched issue, which may require further attention and psychological intervention. However, the results of the study may open a door for further studies focusing on investing time saved by adopting flipped learning model to direct efforts to helping students specifically to deal with procrastination.

\section{REFERENCES}

[1] Akpur, U., Predictive and Explanatory Relationship Model between Procrastination, Motivation, Anxiety and Academic Achievement Eurasian Journal of Educational Research, 2017(69): p. 221-240.

[2] Wäschlea, K., et al., Effects of visual feedback on medical students' procrastination within web-based planning and reflection protocols. Computers in Human Behavior, 2014. 41: p. 120-136.

[3] Hedin, B., Teaching Procrastination -A Way of Helping Students to Improve their Study Habits, in Improving Student Learning symposium. 2012: Lund, Sweden.

[4] Pychyl, T.A., Solving the Procrastination Puzzle. 2013, New York: Penguin Group.

[5] Lay, C. and S. Silverman, Trait Procrastination, Anxiety, and Dilatory Behavior. Personality and Individual Differences, 1995. 21(1): p. 61-67.

[6] Solomon, L. and E. Rothblum, Academic procrastination: Frequency and cognitive-behavioral correlates. Journal of counseling psychology, 1984. 31(4): p. 503-509.

[7] Steel, P., The nature of procrastination: A meta-analytic and theoretical review of quintessential self-regulatory failure.
Psychological bulletin, 2007. 133(1): p. 65-94.

[8] Rushkoff, D., Present shock : when everything happens now. 2013, New York: Penguin Group.

[9] Klassen, R.M., et al., Academic procrastination in two settings: Motivation correlates, behavioral patterns, and negative impact of procrastination in Canada and Singapore. Applied Psychology: An International Review, 2010. 59(3): p. 361-379.

[10] Seo, E.H., The relationships among procrastination, flow, and academic achievement. Social Behavior and Personality, 2011. 39(2): p. 209-218.

[11] Topman, R.M., D. Kruise, and S. Beijne, Digital Coaching of Procrastinators in an Academic Setting, in Counseling the procrastinator in academic settings, H.C. Schouwenburg, et al., Editors. 2004, American Psychological Association: Washington, DC. p. 133-148.

[12] You, J. W., Examining the Effect of Academic Procrastination on Achievement Using LMS Data in e-Learning. Educational Technology \& Society, 2015. 18(3): p. 64-74.

[13] Steel, P., The nature of procrastination: a meta-analytic and theoretical review of quintessential self-regulatory failure. Psychological Bulletin, 2007. 133(1): p. 56-94.

[14] Ghazal, M.A., Academic Procrastination: Prevalence and Causes from the Point of View of Undergraduate Students. Jordan Journal of Educational Sciences, 2012. 8(2): p. 131-149.

[15] Kim, K.R. and E.H. Seo, The relationship between procrastination and academic performance: A meta-analysis. Personality and Individual Differences, 2015. 82: p. 26-33.

[16] Jiao, Q.G., et al., Academic procrastination and the performance of graduate-level cooperative groups in research methods courses. Journal of the Scholarship of Teaching and Learning, 2011. 11(1): p. 119-138.

[17] Kim, S., S. Fernandez, and L. Terrier, Procrastination, personality traits, and academic performance: When active and passive procrastination tell a different story. Personality and Individual Differences, 2017. 108: p. 154-157.

[18] Morrisab, P.E. and C.O. Fritz, Conscientiousness and procrastination predict academic coursework marks rather than examination performance. Learning and Individual Differences, 2015. 39: p. 193-198.

[19] Roig, M. and L. Detommaso, Are College Cheating and Plagiarism Related to Academic Procrastination? Psychological Reports, 1995. 77(2): p. 691-698.

[20] Lay, C. and H.C. Shouwenburg, Trait Procrastination, Time management, and Academic Behavior. Journal of Social Behavior and Personality, 1993. 8(4): p. 647-662.

[21] Brownlow, S. and R. Reasinger, Putting off until tomorrowwhat is betterdone today: academic procrastination as a function of motivationtowardcollege work. Journal of Social Behavior and Personality, 2000. 15: p. 15-34.

[22] Schouwenburg, H.C., Academic procrastination: Theoretical notions, measurement, and research, in counseling the procrastinator in academic settings, H.C. Schouwenburg, et 
al., Editors. 2004, American Psychological Association: Washington, DC. p. 3-17.

[23] Ugurlu, C.T., Effects of Decision- Making Styles of School Administrators on General Procrastination Behaviors. Euraasian Journal of Educational Research, 2013. Spring(51): p. 253-272.

[24] Senécal, C., R. Koestner, and R.J. Vallerand, Self-Regulation and Academic Procrastination. The Journal of Social Psychology, 1995. 135(5): p. 607--619.

[25] Lee, E., The Relationship of Motivation and Flow Experience to Academic Procrastination in University Students. The Journal of Genetic Psychology, 2005. 166(1): p. 5-15.

[26] Ryan, R.M., Psychological Needs and the Facilitation of Integrative Processes. Journal qf Personality, 1995. 63(3): p. 397-427.

[27] Haghbin, M., A. McCaffrey, and T.A. Pychyl, The Complexity of the Relation between Fear of Failure and Procrastination. Journal of Rational-Emotive \& Cognitive-Behavior Therapy, 2012. 30(4): p. 249-263.

[28] Ryan, R.M. and E.L. Deci, Self-determination theory and the facilitation of intrinsic motivation, social development, and well-being. American Psychologist, 2000. 55(1): p. 68-78.

[29] Odaci, H., Academic self-efficacy and academic procrastination as predictors of problematic internet use in university students. Computers \& Education, 2011. 57: p. 1109-1113.

[30] Selwyn, N., Digital downsides: exploring university students' negative engagements with digital technology. Teaching in Higher Education, 2016. 21(8): p. 1006-1021.

[31] Gilroy, M., Invasion of the classroom cell phones. Education Digest, 2004. 69(6): p. 56-60.

[32] Katz, J., Mobile phones in educational settings, in A sense of place: Thegobal and the local in mobile communication, $\mathrm{K}$. Nyiri, Editor. 2005, Passagen: Vienna. p. 305-317.

[33] Alwagait, E., B. Shahzad, and S. Alim, Impact of social media usage on students academic performance in Saudi Arabia. Computers in Human Behavior, 2015. 51(B): p. 1092-1097.

[34] Zax, D., Learning in 140-Characters Bites. ASEE Prism, 2009. 19(2): p. 51-52.

[35] Shatto, B. and K. Erwin, Moving on From Millennials: Preparing for Generation Z. The Journal of Continuing Education in Nursin, 2016. 47(6): p. 253-254.

[36] Roseberry-McKibbin, C., et al., Effective Pedagogical Strategies for Millennial University Students in Communication Sciences and Disorders: Student Survey Results. Communication Disorders Quarterly, 2016. 37(3): p. $180-183$.

[37] Owusu-Acheaw, M. and A.G. Larson, Use of Social Media and its Impact on Academic Performance of Tertiary Institution Students: A Study of Students of Koforidua Polytechnic, Ghana. Journal of Education and Practice, 2015. 6(6): p. 94-101.

[38] Ketari, L.M. and M.A. Khanum, Impact of Facebook Usage on the Academic Grades: A Case Study. Journal of Computing, 2013. 5(1): p. 44-48.

[39] Westwood, P., Teaching and learning difficulties : cross-curricular perspectives. 2006, Camberwell, Victoria, Australia: ACER Press.

[40] Cannon, R. and D. Newble, A Handbook For Teachers In Universities \& Colleges. 4th ed. 2000, Milton Park, Abingdon: RoutledgeFalmer.

[41] Nouri, J., The flipped classroom: for active, effectiveand increased learning-especially for low achievers. International Journal of Educational Technology in Higher Education, 2016. 13(1): p. 33.

[42] McLean, S., et al., Flipped classrooms and student learning: not just surface gains. The American Physiological Society, 2016. 40(1): p. 47-55.

[43] Uzun, B., J.R. Ferrari, and S. LeBlanc, Put Aside Procrastination: Positive Emotional Outcomes from Self-Forgiveness for Delays. North American Journal of Psychology, 2018. 20(1): p. 171-186.

[44] Abuhmaid, A., The Impact of Using Flipped Learning Strategy on Students' Motivation for Learning, in 10th annual International Conference of Education, Research and Innovation. 2017: Seville (Spain).

[45] Chao, C.Y., Y.T. Chen, and K.Y. Chuang, Exploring students' learning attitude and achievement in flipped learning supported computer aided design curriculum: A study in high school engineering education. Computer Applications in Engineering Education, 2015. 23(4): p. 514-526.

[46] Baeten, M., F. Dochy, and K. Struyven, The effects of different learning environments on students' motivation for learning and their achievement. British Journal of Educational Psychology, 2013. 83(3): p. 484-501.

[47] Jensen, J.L., T.A. Kummer, and P.D.d.M. Godoy, Improvements from a Flipped Classroom May Simply Be the Fruits of Active Learning. Life Sciences Education, 2015. 14(1): p. 1-12.

[48] Abeysekera, L. and P. Dawson, Motivation and cognitive load in the flipped classroom: definition, rationale and a call for research. Higher Education Research \& Development, 2015. 34(1): p. 1-14.

[49] Bergmann, J. and A. Sams, Flip your classroom : reach every student in every class every day. 2012, Washington, DC: ISTE.

[50] Bergmann, J., J. Overmyer, and B. Wilie The Flipped Class: Myths vs. Reality. 2013. 2013.

[51] Mazur, E., Farewell, Lecture? SCIENCE Magazine, 2009. 323: p. 50-51.

[52] Mazur, A.D., B. Brown, and M. Jacobsen, Learning Designs Using Flipped Classroom Instruction. Canadian Journal of Learning \& Technology, 2015. 41(2).

[53] Bristol, T.J., Flipping the Classroom. Teaching and Learning in Nursing, 2014. 9(1): p. 43-46.

[54] Klatzky, R.L., et al., Touch-Screen Technology for the Dynamic Display of 2D Spatial Information Without Vision: 
Promise and Progress. Multisensory Research, 2014. 27(5-6): p. 359-378.

[55] Flipped Learning Network. The Four Pillars of F-L-I-P. 201425 August, 2018]; Available from: https://flippedlear ning.org/definition-of-flipped-learning/.

[56] White, C., et al., Challenges to Engaging Medical Students in a Flipped Classroom Model. Medical Science Educator, 2015. 25(3): p. 219-222.

[57] James, A.J., C.K.H. Chin, and B.R. Williams, Flipped classroom use to improve and prepare maritime graduates. Journal of Maritime Affairs, 2014. 13(2): p. 331-343.

[58] Herreid, C.F. and N.A. Schiller, Case Studies and the Flipped Classroom. Journal of College Science Teaching 2013. 42(5): p. 62-66.

[59] Butt, A., Student views on the use of a flipped classroom approach: evidence from Australia. Business Education \& Accreditation, 2014. 6(1): p. 33-43.

[60] Pew Research Center, Internet's Broader Role in Campaign 2008: Social Networking and Online Videos Take Off. 2008.

[61] Zhang, D., et al., Instructional video in e-learning: Assessing the impact of interactive video on learning effectiveness. Information \& Management, 2006. 43(1): p. 15-27.

[62] Nielsen, P.L., N.W. Bean, and R.A.A. Larsen, The Impact of a Flipped Classroom Model of Learning On a Large Undergraduate Statistics Class Statistics Education Research Journal, 2018. 17(1): p. 121-140.

[63] Fadol, Y., H. Aldamen, and S. Saadullah, A comparative analysis of flipped, online and traditional teaching: A case of female Middle Eastern management students. The International Journal of Management Education, 2018. 16(2): p. 266-280.

[64] Roehl, A., S.L. Reddy, and G.J. Shannon, The flipped classroom: an opportunity to engage millennial students through active learning strategies. 2013. 105(2): p. 44-49.

[65] AlJarrah, A., M.K. Thomas, and M. Shehab, Investigating temporal access in a flipped classroom: procrastination persists. International Journal of Educational Technology in Higher Education, 2018. 15(1): p. 1-18.

[66] Tuckman, B.W., The Development and Concurrent Validity of the Procrastination Scale. Educational and Psychological Measurement, 1991. 51: p. 473-480.

[67] Tuckman, B. and T.L. Sexton, The relation between self-beliefs and self-regulated performance. Journal of Social Behavior and Personality, 1990. 5(5): p. 365.

[68] Popoola, B.I., A Study of Procrastinatory Behaviour and Academic Performance of Undergraduate Students in South Western Nigeria. Journal of Social Sciences, 2005. 11(5): p. 215-218.

[69] Thatchera, A., G. Wretschkoa, and P. Fridjhon, Online flow experiences, problematic Internet use and Internet procrastination. Computers in Human Behavior 2008. 24(5): p. 2236-2254.

[70] Mooring, S.R., C.E. Mitchell, and N.L. Burrows, Evaluation of a Flipped, Large-Enrollment Organic Chemistry Course on Student Attitude and Achievement. Chemical Education, 2016. 93(12). 